\title{
Solvent Extraction of Lanthanide Ions with a Diglycolamic Acid Extractant Based on D-Glucosamine
}

\author{
Takahide NAKAMURA, Natsuki HIGA, Syouhei NISHIHAMA*, and Kazuharu YOSHIZUKA \\ Department of Chemical Engineering, The University of Kitakyushu, \\ Hibikino 1-1, Kitakyushu 808-0135, Japan \\ (Received December 25, 2009; Accepted January 31, 2010)
}

2-Deoxy-2-carboxymethoxy-acetylamino-1,3,4,6-tetra-O-decanoyl- $D$-glucopyranose (C9GLNDGAA; RH) has been developed for the extraction of lanthanide ions from aqueous nitrate solution. The present extractant extracts lanthanide ions (M) by two types of extraction mechanism. The extracted species are determined to be $\mathrm{MR}_{3}(\mathrm{RH})_{3}$ for the lighter ions from $\mathrm{La}^{3+}$ to $\mathrm{Sm}^{3+}$, and $\mathrm{MR}_{2}(\mathrm{RH})_{2} \mathrm{NO}_{3}$ for the heavier ions from $\mathrm{Eu}^{3+}$ to $\mathrm{Yb}^{3+}$. The extraction of lanthanide ions seems to be directly affected by the steric hindrance of the glucosamine framework.

\section{Introduction}

Biomolecules, such as sugar, amino acids and DNA, have several functional groups for specific recognition of metal ions. The biomolecules coordinating with metal ions have also "lead generation" potential available for new extractants. $D$-glucosamine as an amino sugar has been widely used in health foods. This compound has not only an active primary amino group for binding with metal ions, but also a number of hydroxyl groups which allow easy introduction of long-chain alkyl groups for hydrophobilizing into the molecule [1].

In previous work, a hydrophobic glucosamine with four decanoyl groups attached to the hydroxyl groups has been developed for extraction of molybdenum and tungsten [2]. The glucosamine extractant has a high separation ability for the oxoanions of tungsten and molybdenum, compared with the commercial amine type extractants such as Primene JM-T and tri- $n$-octylamine, due to the steric hindrance of the bulky alkyl chains introduced into the glucosamine framework. This suggests that $D$-glucosamine has sufficient potential as a framework for new metal extractants offering the possibility of unique extraction behavior for metal ions. 
Lanthanide ions have similar chemical and physical properties, and there is little difference in their ionic radii, resulting in differences in mutual separation of the lanthanide ions. Many extractants have been developed for the industrial hydrometallurgical separation of lanthanide ions, e.g., acidic organophosphorus [3] and carboxylic acid type compounds [4]. In addition, bimolecular-based extractants have also been applied to lanthanide extraction and the evaluation of their extraction and separation abilities has been reported. Thus, Shimojo et al. have investigated the extraction of a series of lanthanide ions with $N, N$-dioctyldiglycolamic acid [5]. They found that $N, N$-dioctyldiglycolamic acid has a high extractability for lanthanide ions compared with typical carboxylic acid compounds. Since this suggests that the diglycolamic acid group has a high affinity for lanthanide ions, we have focused on it as an ion exchange group in the present extractant.

In the present work, hydrophobic glucosamine with a diglycolamic acid group, 2-deoxy-2-carboxymethoxy-acetylamino-1,3,4,6-tetra-O-decanoyl- $D$-glucopyranose (abbrebiated as C9GLNDGAA, hereafter) was developed as an extractant for lanthanide ions. The extraction behavior of trivalent lanthanide ions from aqueous nitrate solutions with C9GLNDGAA was investigated in a conventional batch extraction system. The extraction equilibria of lanthanide ions were investigated by the slope analysis method, loading tests, and the continuous variation method to evaluate the equilibrium stoichiometry based on the coordination of glucosamine with the lanthanide ions.

\section{Experimental}

\subsection{Synthesis of the extractant}

$D$-Glucosamine hydrochloride, $n$-decanoic anhydride, 4-dimethylaminopyridine and diglycolic anhydride were supplied by Tokyo Chemical Industry. Pyridine, $p$-anisaldehyde, all inorganic reagents, and organic solvents were supplied by Wako Pure Chemical Industries.

The synthetic route is shown in Scheme 1. The compounds from 1 to 3 were synthesized according to the procedures reported in a previous paper [2].

\section{2-Deoxy-2-carboxymethoxy-acetylamino-1,3,4,6-tetra-O-decanoyl-D-glucopyranose (4), C9GLNDGAA}

Diglycolic anhydride (0.092 g, 1.26 eq.) was suspended in $15 \mathrm{~mL}$ of dichloromethane. A solution of product $3(0.5 \mathrm{~g}, 0.628 \mathrm{mmol})$ in $5 \mathrm{~mL}$ of dichloromethane was slowly added to the suspention in an ice bath under a nitrogen atomosphere. The mixture was stirred for $24 \mathrm{~h}$ at room temperature. The organic layer was collected and washed with deionized water. The organic solution was dried with anhydrous magnesium sulfate. After filtration, the solvent was evaporated and the resulting solid dried in vacuo to obtain a white film solid (0.95 g, $82.9 \%$ yield). The product was identified by ${ }^{1} \mathrm{H}-\mathrm{NMR}$ spectrometry (JEOL, JMM-ECP500) and FT-IR spectrometry (Shimadzu, FTIR-8400S). ${ }^{1} \mathrm{H}-\mathrm{NMR}\left(500 \mathrm{MHz}, \mathrm{CDCl}_{3}\right) \delta 7.03$ (d, $J=9.6,1 \mathrm{H}), 5.73(\mathrm{~d}, J=8.7,1 \mathrm{H}), 5.22(\mathrm{t}, J=10.1,1 \mathrm{H}), 5.11(\mathrm{t}, J=9.9,1 \mathrm{H}), 4.26(\mathrm{~m}, 1 \mathrm{H}), 4.16(\mathrm{~m}, 1 \mathrm{H})$, 3.96-4.06 (m, 4H), $3.82(\mathrm{~d}, J=10.1,1 \mathrm{H}), 2.22(\mathrm{~m}, 8 \mathrm{H}), 1.50(\mathrm{~m}, 8 \mathrm{H}), 1.20(\mathrm{br}, 48 \mathrm{H}), 0.81(\mathrm{t}, J=6.9,12 \mathrm{H})$; 
FT-IR (KBr) 3335, 2950, 2975, 2850, 1750, 1650, 1540, 1075-1253 $\mathrm{cm}^{-1}$. An elemental analysis (Yanaco, MT-6 Corder) gave the following result: found $\mathrm{C}, 65.09, \mathrm{H}, 9.74, \mathrm{~N}, 1.70 \%$, calculated for $\mathrm{C}_{50} \mathrm{H}_{89} \mathrm{NO}_{13}$ : C, $65.83, \mathrm{H}, 9.83, \mathrm{~N}, 1.54 \%$.

\subsection{Apparent molecular weight of C9GLNDGAA}

The ESI-TOF mass spectrum of C9GLNDGAA in toluene was recorded with an electro spraying injection type time-of-flight mass spectrometer (ESI-TOF MS; Applied biosystems model Mariner ${ }^{\mathrm{TM}}$ biospectrometry workstation). The apparent molecular weight of C9GLNDGAA in toluene was determined at $60{ }^{\circ} \mathrm{C}$ with a vapor-phase osmometer (VPO; Corona model 114), using benzil as a standard material.

\subsection{Extraction procedure}

The organic solution was prepared by dissolving C9GLNDGAA in toluene. Aqueous solutions were prepared by dissolving lanthanide nitrates ( $\mathrm{La}, \mathrm{Ce}, \mathrm{Pr}, \mathrm{Nd}, \mathrm{Sm}, \mathrm{Eu}, \mathrm{Gd}, \mathrm{Y}, \mathrm{Er}$, and $\mathrm{Yb}$ ) in deionized water. In the present extraction system, the $\mathrm{pH}$ was adjusted by adding the appropriate amount of nitric acid solution to a HEPES [2-(4-(2-hydroxyethyl)-1-piperazinyl) ethane sulfonic acid] aqueous buffer solution. Equal volumes of the aqueous and organic solutions were shaken vigorously at $25{ }^{\circ} \mathrm{C}$ for more than $3 \mathrm{~h}$ to attain equilibrium. After phase separation, the equilibrium $\mathrm{pH}$ value was measured using a $\mathrm{pH}$ meter (Horiba model F-23). The concentration of metal ions was analyzed using an inductively coupled plasma atomic emission spectrometer (ICP-AES; Shimadzu model ICPS-7000). The concentrations in the organic solutions were calculated from the material valance.

2.5 Stripping tests for $\mathrm{La}^{3+}, \mathrm{Eu}^{3+}$ and $\mathrm{Yb}^{3+}$

Equal volumes of the metal-loaded organic solution and various concentrations of nitric acid solution were mixed, and then were shaken vigorously at $25{ }^{\circ} \mathrm{C}$ for more than $12 \mathrm{~h}$ to attain equilibrium.

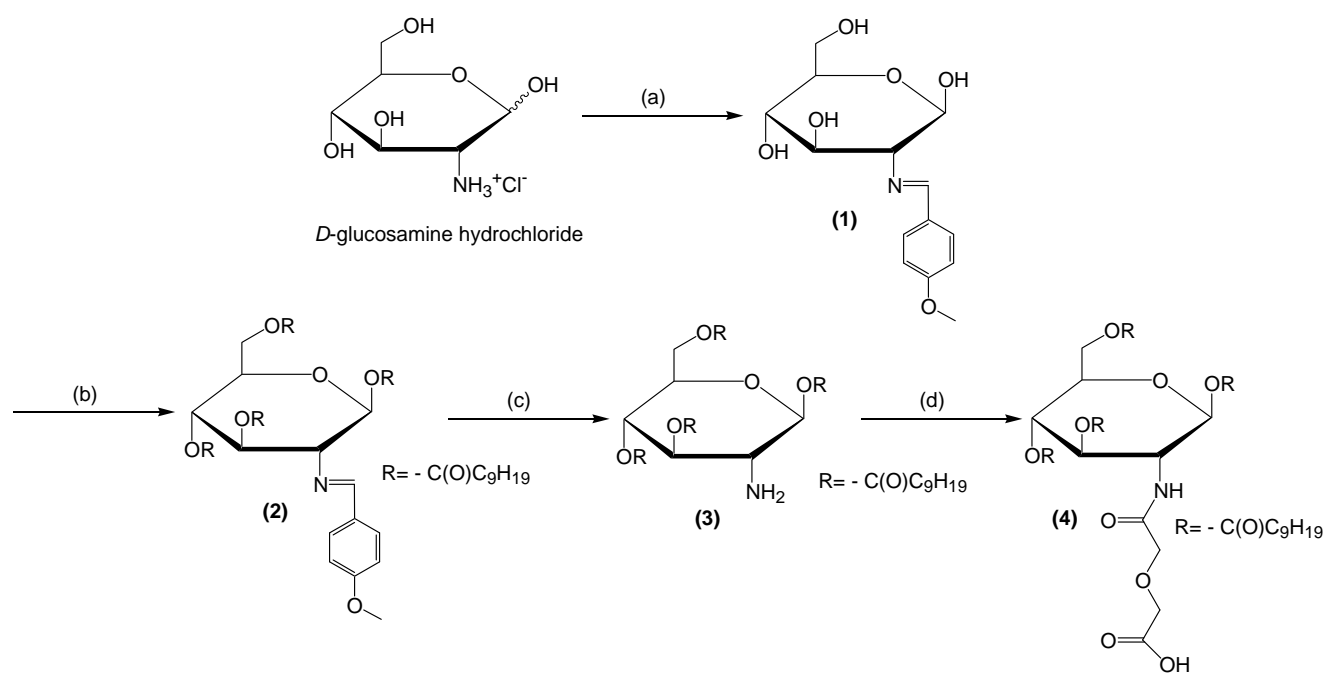

Scheme 1 Synthetic route for the present extractant; (a) $p$-methoxybenzaldehyde (reactant), $\mathrm{NaOH}$ (reactant), $\mathrm{H}_{2} \mathrm{O}$ (solvent), (b) $n$-decanoic anhydride (reactant), 4-dimethylaminopyridine (catalyst), pyridine (solvent), (c) (i) $6 \mathrm{~mol} / \mathrm{L} \mathrm{HCl}$ (reactant), acetone (solvent), (ii) $28 \% \mathrm{NH}_{3}$ (reactant), toluene (reactant), (d) diglycolic anhydride (reactant), $\mathrm{CH}_{2} \mathrm{Cl}_{2}$ (solvent). 
After phase separation, the concentration of metal ions was analyzed using ICP-AES.

\section{Results and Discussion}

\subsection{Dimerization of C9GLNDGAA}

Figure 1 shows the ESI-TOF mass spectrum of C9GLNDGAA in toluene. The peaks at $\mathrm{m} / \mathrm{z}=934$ and 1846 in the spectrum were assigned to the monomer and dimer of C9GLNDGAA fragments, respectively, although a small deviation from the theoretical molecular weight, probably due to experimental error, is observed. This indicates that C9GLNDGAA exists as the mixture of monomeric and dimeric species in toluene. The apparent average molecular weight of

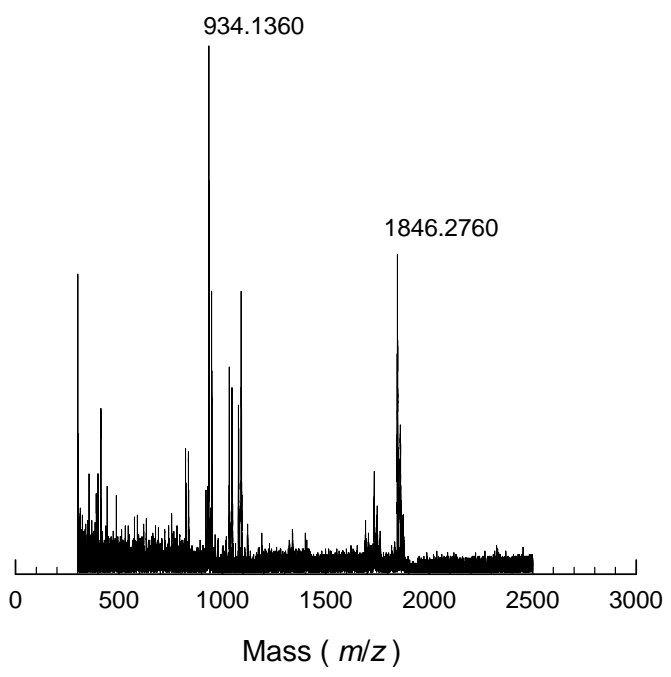

Fig. 1 ESI-TOF mass spectrum of C9GLNDGAA in toluene. C9GLNDGAA in toluene at $60{ }^{\circ} \mathrm{C}$ was measured with VPO and was determined to be $1557 \mathrm{~g} / \mathrm{mol}$, while the molecular weight of C9GLNDGAA as a monomeric species is $912.2 \mathrm{~g} / \mathrm{mol}$. This indicates that $71 \%$ of C9GLNDGAA exists as the dimeric species in toluene. Most of C9GLNDGAA is expected to exist as the dimeric species at $25{ }^{\circ} \mathrm{C}$, since the aggregation of the extractant increases with decreasing temperature [6].

\subsection{Extraction equilibria of lanthanide ions in single metal systems}

Figure 2 shows the effect of shaking time on the percent extraction of $\mathrm{La}^{3+}, \mathrm{Eu}^{3+}$ and $\mathrm{Yb}^{3+}$ with C9GLNDGAA. Extraction equilibria for these metal ions were achieved within $3 \mathrm{~h}$. Figure 3 shows the effect of $\mathrm{pH}$ on the distribution ratios $(D)$ of the lanthanide ions, together with the slope values of the $\mathrm{pH}$ dependency in Table 1. Straight lines with a slope of 3 were observed for the lighter lanthanide ions, $\mathrm{La}^{3+}$, $\mathrm{Ce}^{3+}, \mathrm{Pr}^{3+}, \mathrm{Nd}^{3+}$ and $\mathrm{Sm}^{3+}$, indicating that the extraction progresses via a cation exchange mechanism. On the other hands, straight lines with a slope of 2 were observed for the heavier lanthanide ions, $\mathrm{Eu}^{3+}, \mathrm{Gd}^{3+}$, $\mathrm{Y}^{3+}, \mathrm{Er}^{3+}$ and $\mathrm{Yb}^{3+}$, suggesting that one nitrate ion $\left(\mathrm{NO}_{3}{ }^{-}\right)$was co-extracted along with the lanthanide ions, to neutralize the charge on the metal ion in the organic phase.

Table 1 Slopes of the $\mathrm{pH}$ dependency for rare earth metal ions

\begin{tabular}{llllllllll}
\hline $\mathrm{La}^{3+}$ & $\mathrm{Ce}^{3+}$ & $\mathrm{Pr}^{3+}$ & $\mathrm{Nd}^{3+}$ & $\mathrm{Sm}^{3+}$ & $\mathrm{Eu}^{3+}$ & $\mathrm{Gd}^{3+}$ & $\mathrm{Y}^{3+}$ & $\mathrm{Er}^{3+}$ & $\mathrm{Yb}^{3+}$ \\
\hline 2.92 & 2.97 & 2.77 & 3.02 & 2.78 & 2.19 & 2.14 & 1.77 & 2.00 & 1.97 \\
\hline
\end{tabular}




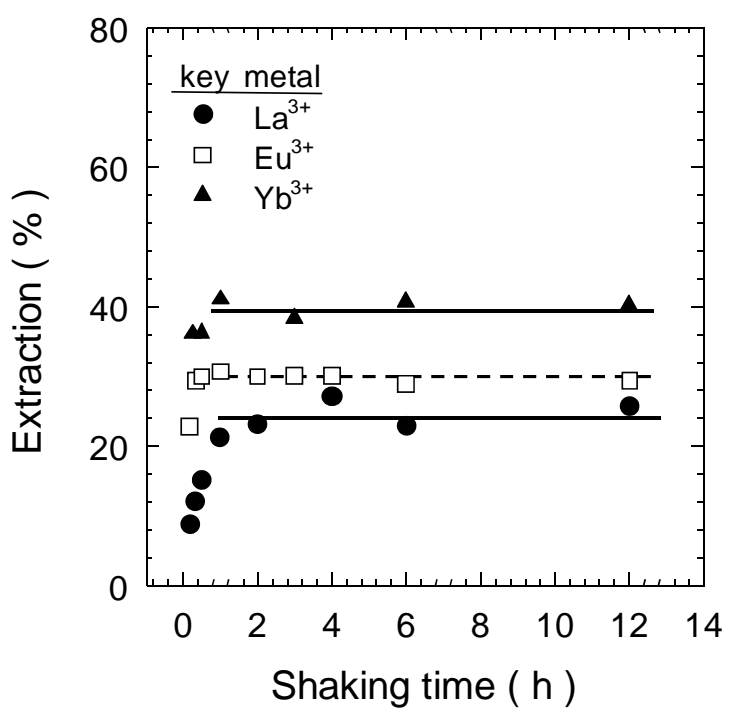

Fig. 2 Effect of shaking time on the percent extraction of $\mathrm{La}^{3+}, \mathrm{Eu}^{3+}$, and $\mathrm{Yb}^{3+}$ with C9GLNDGAA; $\left[\mathrm{M}^{3+}\right]_{\text {inital }}=0.05 \mathrm{mmol} / \mathrm{L}$, $\left[\overline{(\mathrm{RH})_{2}}\right]_{\text {initial }}=2.5 \mathrm{mmol} / \mathrm{L},\left[\mathrm{NO}_{3}{ }^{-}\right]=0.1 \mathrm{~mol} / \mathrm{L}$, $\mathrm{pH}_{\mathrm{La}}=4.37 \pm 0.03, \mathrm{pH}_{\mathrm{Eu}}=4.02 \pm 0.01$ and $\mathrm{pH}_{\mathrm{Yb}}$ $=4.15 \pm 0.03$.

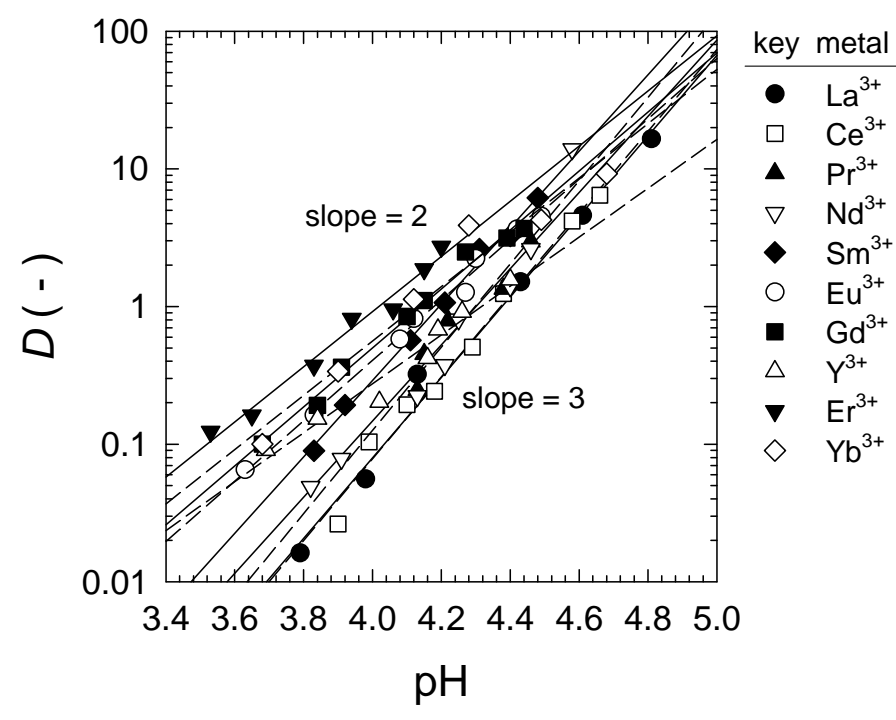

Fig. 3 Effect of $\mathrm{pH}$ on the distribution ratios of lanthanide ions with C9GLNDGAA; $\left[\mathrm{M}^{3+}\right]_{\text {initial }}=$ $0.05 \mathrm{mmol} / \mathrm{L}, \quad\left[\overline{(\mathrm{RH})_{2}}\right]_{\text {initial }}=2.5 \mathrm{mmol} / \mathrm{L}$, $\left[\mathrm{NO}_{3}{ }^{-}\right]=0.1 \mathrm{~mol} / \mathrm{L}$.

The stoichiometry of the extracted complexes was determined by slope analysis, Job's method, and by loading tests. Figure 4 shows the effect of the dimeric concentration of the extractant in organic phase $\left(\left[\overline{(\mathrm{RH})_{2}}\right]\right)$ on the distribution ratio, $D\left[\mathrm{H}^{+}\right]^{n}\left(n=3\right.$ for $\mathrm{La}^{3+}$ and $\mathrm{Sm}^{3+}, n=2$ for $\mathrm{Eu}^{3+}$ and $\left.\mathrm{Yb}^{3+}\right)$. Straight lines with a slope of 3 for $\mathrm{La}^{3+}$ and $\mathrm{Sm}^{3+}$ and a slope of 2 for $\mathrm{Eu}^{3+}$ and $\mathrm{Yb}^{3+}$ were obtained. Figure 5 shows Job's plot for $\mathrm{La}^{3+}, \mathrm{Eu}^{3+}$ and $\mathrm{Yb}^{3+}$ [7]. Maximum extraction occurred at a molar fraction of 0.75 for $\mathrm{La}^{3+}$ and at 0.67 for $\mathrm{Eu}^{3+}$ and $\mathrm{Yb}^{3+}$. Figure 6 shows the effect of the initial concentration of lanthanide ions in the aqueous solution $\left([\mathrm{M}]_{\text {initial }}\right.$ ) on the ratio of the initial concentration of the extractant in toluene to the equilibrium concentrations of the lanthanide ions in the organic phase $\left(\left[\overline{(\mathrm{RH})_{2}}\right]_{\text {initial }} /[\overline{\mathrm{M}}]\right)$ in the loading tests. The ratio of $\left[\overline{(\mathrm{RH})_{2}}\right]_{\text {initial }} /[\overline{\mathrm{M}}]$ reached 3 for $\mathrm{La}^{3+}$ and 2 for $\mathrm{Eu}^{3+}$ and $\mathrm{Yb}^{3+}$ with increasing initial metal concentration. Based on these results, the stoichiometry of the metal complexes extracted is $\left[\overline{(\mathrm{RH})_{2}}\right]:\left[\mathrm{M}^{3+}\right]=3: 1$ for the lighter lanthanide ions from $\mathrm{La}^{3+}$ to $\mathrm{Sm}^{3+}$ and $\left[\overline{(\mathrm{RH})_{2}}\right]:\left[\mathrm{M}^{3+}\right]=2: 1$ for the heavier lanthanide ions from $\mathrm{Eu}^{3+}$ to $\mathrm{Yb}^{3+}$. The extraction equilibria for the lanthanide ions are therefore expressed by Eqs.(1) and (2).

$$
\begin{aligned}
& \mathrm{M}^{3+}+3 \overline{(\mathrm{RH})_{2}} \longleftrightarrow \overline{\mathrm{MR}_{3}(\mathrm{RH})_{3}}+3 \mathrm{H}^{+}\left(\mathrm{M}=\mathrm{La}^{3+} \text { to } \mathrm{Sm}^{3+}\right) \\
& \mathrm{M}^{3+}+2 \overline{(\mathrm{RH})_{2}}+\mathrm{NO}_{3}{ }^{-} \longleftrightarrow \overline{\mathrm{MR}_{2}(\mathrm{RH})_{2} \mathrm{NO}_{3}}+2 \mathrm{H}^{+}\left(\mathrm{M}=\mathrm{Eu}^{3+} \text { to } \mathrm{Yb}^{3+}\right)
\end{aligned}
$$


Figure 7 shows the possible structures of the lanthanide complexes with C9GLNDGAA according to the above equations. Although the diglycolamic acid group possibly acts as a tridentate ligand, it is considered to act as a monodentate ligand in the present extraction system due to its bulky structure and lower extraction ability compared with a diglycolamic acid type extractant [5]. The bond length between the central metal ion and the donor elements generally decreases with decreasing ionic radius [8]. The extractant having a rigid framework with bulky groups may also tightly coordinate with smaller (heavier) lanthanide ions, leading to two types of metal complex. The steric hindrance of the extractant therefore affects the extraction mechanism for a series of lanthanide ions.
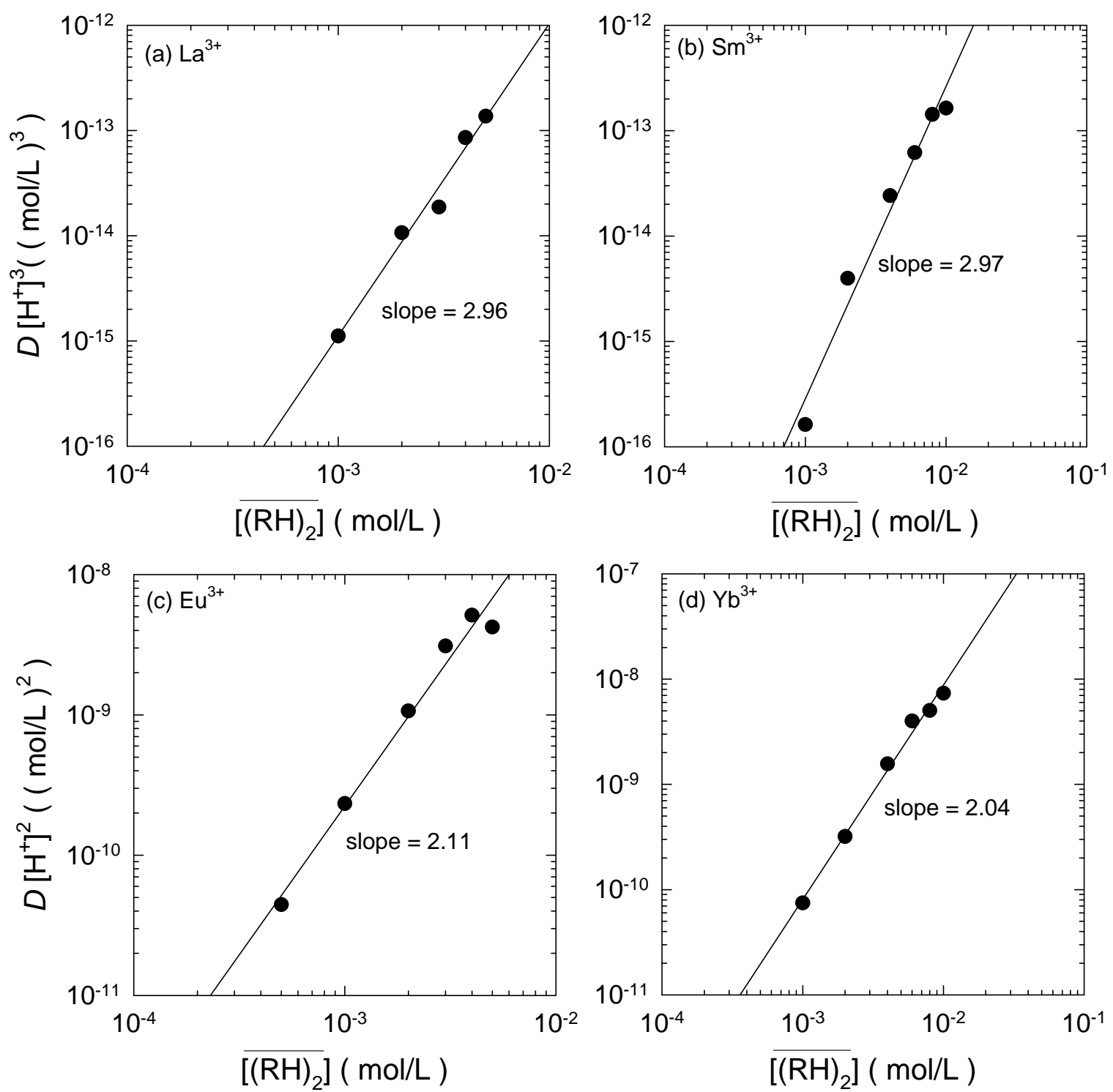

Fig. 4 Effect of extractant concentration on the distribution ratios of (a) $\mathrm{La}^{3+}$, (b) $\mathrm{Sm}^{3+}$, (c) $\mathrm{Eu}^{3+}$ and (d) $\mathrm{Yb}^{3+} ;\left[\mathrm{M}^{3+}\right]_{\text {initial }}=0.05 \mathrm{mmol} / \mathrm{L},\left[\mathrm{NO}_{3}^{-}\right]=0.1 \mathrm{~mol} / \mathrm{L}, \mathrm{pH}_{\mathrm{La}}=4.53 \pm 0.02, \mathrm{pH}_{\mathrm{Sm}}=4.56 \pm 0.03, \mathrm{pH}_{\mathrm{Eu}}=$ $4.59 \pm 0.04$ and $\mathrm{pH}_{\mathrm{Yb}}=4.57 \pm 0.02$. 

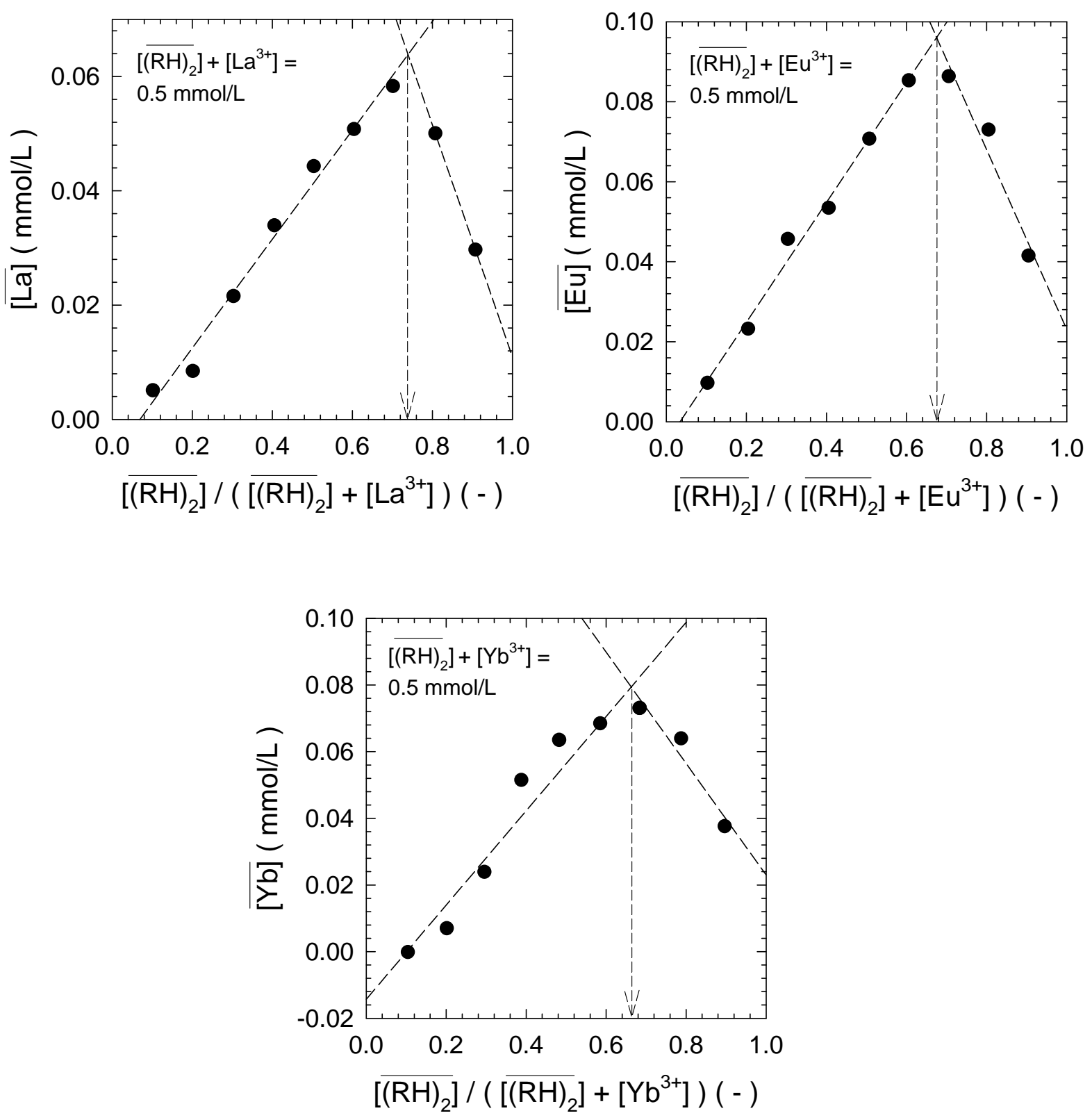

Fig. 5 Job's plots for $\mathrm{La}^{3+}, \mathrm{Eu}^{3+}$, and $\left.\mathrm{Yb}^{3+} ; \overline{(\mathrm{RH})_{2}}\right]+\left[\mathrm{M}^{3+}\right]=0.5 \mathrm{mmol} / \mathrm{L}, \mathrm{pH}_{\mathrm{La}}=5.31 \pm$ $0.02, \mathrm{pH}_{\mathrm{Eu}}=5.24 \pm 0.06$ and $\mathrm{pH}_{\mathrm{Yb}}=5.22 \pm 0.06$. 


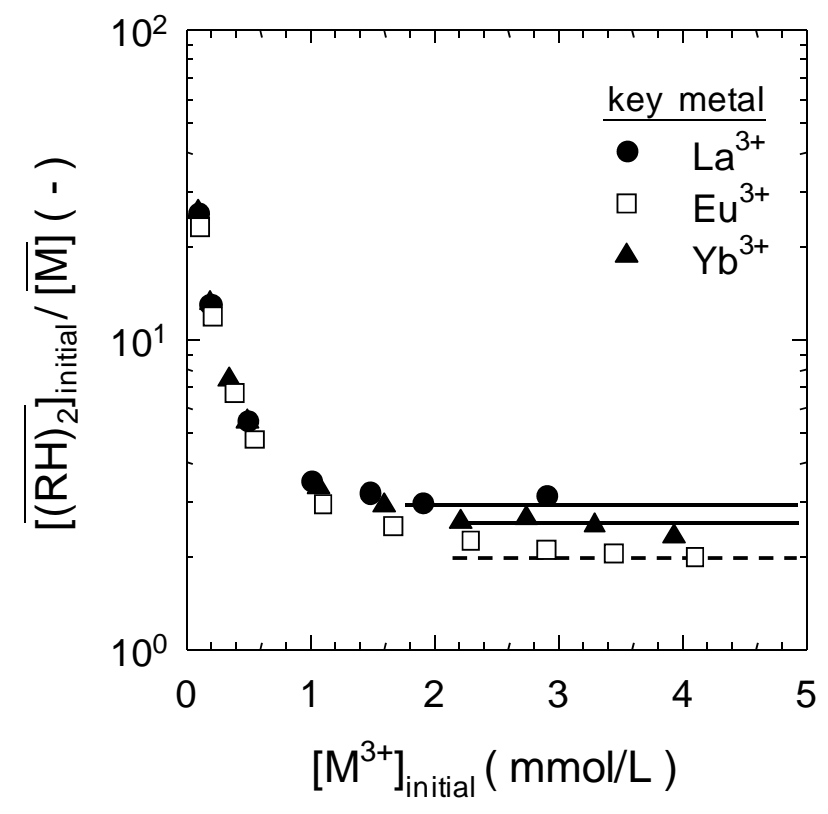

Fig. 6 Loading tests for $\mathrm{La}^{3+}, \mathrm{Eu}^{3+}$ and $\mathrm{Yb}^{3+} ;\left[\overline{(\mathrm{RH})_{2}}\right]_{\text {initial }}=2.5 \mathrm{mmol} / \mathrm{L}$.
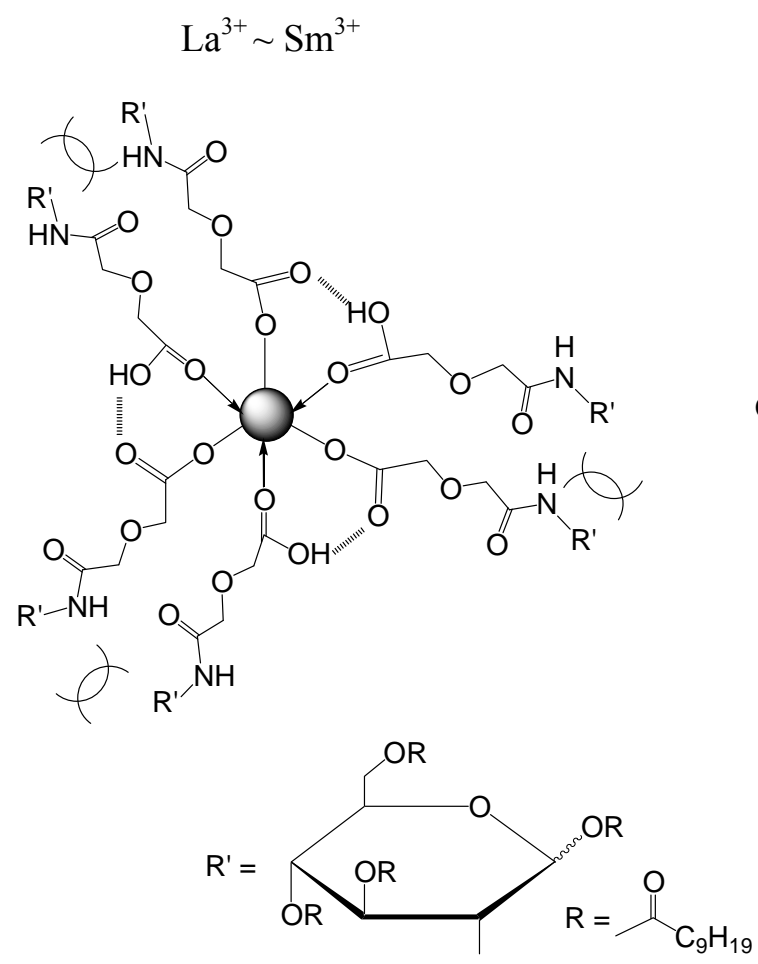

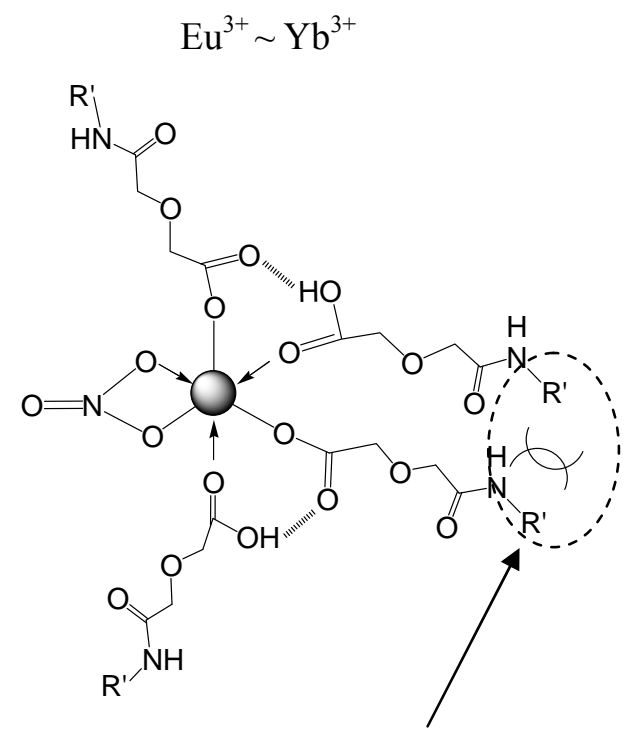

Steric hindrance

Fig. 7 Possible structures of the extracted complexes. 


\subsection{Stripping of $\mathrm{La}^{3+}$, $\mathrm{Eu}^{3+}$ and $\mathrm{Yb}^{3+}$}

Table 2 shows the degree of stripping of $\mathrm{La}^{3+}, \mathrm{Eu}^{3+}$ and $\mathrm{Yb}^{3+}$ with several concentrations of nitric acid as the stripping reagent. The loaded lanthanide ions in organic solution were quantitatively stripped by using a relatively low concentration $(\sim 0.01 \mathrm{~mol} / \mathrm{L})$ of nitric acid. The stripping efficiencies were slightly decreased with $1.0 \mathrm{~mol} / \mathrm{L}$ of nitric acid. This suggests that the stripping reaction was inhibited by the undissociated extractant via the solvating extraction of lanthanoid ions.

Table 2 Stripping tests for $\mathrm{La}^{3+}, \mathrm{Eu}^{3+}$, and $\mathrm{Yb}^{3+}$ with nitric acid solutions

\begin{tabular}{cccc}
\hline \multirow{2}{*}{ Concentration $(\mathrm{mol} / \mathrm{L})$} & \multicolumn{3}{c}{ Stripping $(\%)$} \\
\cline { 2 - 4 } & $\mathrm{La}^{3+}$ & $\mathrm{Eu}^{3+}$ & $\mathrm{Yb}^{3+}$ \\
\hline 0.01 & 100 & 100 & 100 \\
\hline 0.1 & 100 & 100 & 100 \\
\hline 1.0 & 81.1 & 98.5 & 95.0 \\
\hline
\end{tabular}

\section{Conclusion}

The extraction behavior of several lanthanide ions with 2-deoxy-2-carboxymethoxy-acetylamino1,3,4,6-tetra-O-decanoyl-D-glucopyranose (C9GLNDGAA) has been investigated, with the following results. The present extractant has two types of extraction mechanism for lanthanide ions, and lanthanide ions from $\mathrm{Eu}^{3+}$ to $\mathrm{Yb}^{3+}$ are extracted together with one nitrate ion. The extracted species are shown to be $\mathrm{MR}_{3}(\mathrm{RH})_{3}$ for the lighter lanthanide ions from $\mathrm{La}^{3+}$ to $\mathrm{Sm}^{3+}$ and $\mathrm{MR}_{2}(\mathrm{RH})_{2} \mathrm{NO}_{3}$ for the heavier lanthanide ions from $\mathrm{Eu}^{3+}$ to $\mathrm{Yb}^{3+}$. In the present extraction system, the steric hindrance of C9GLNDGAA are directly affects coordination with the lanthanide ions. $D$-glucosamine is therefore concluded to be an attractive framework for extracting various kinds of metal ions.

\section{Acknowledgement}

The authors are grateful to Professor Junji Fukuda of Graduate School of Pure and Applied Sciences, University of Tsukuba for the VPO measurements of the extractant at the Chemical Analysis Division, Research Facility Center for Science and Technology, University of Tsukuba. The ESI-TOF MS and ${ }^{1} \mathrm{H}$-NMR measurements were performed at the Instrumentation Center, The University of Kitakyushu.

\section{References}

1) D. J. Silva, H. Wang, N. M. Allanson, R. K. Jain, M. J. Sofia, J. Org. Chem., 64, 5926-5929 (1999).

2) T. Nakamura, S. Nishihama, K. Yoshizuka, Solv. Extr. Res. Dev., Japan, 16, 47-56 (2009).

3) (a) Z. Kolarík, H. Pánková, J. Inorg. Nucl. Chem., 28, 2325-2333 (1966). (b) Z. Kolaríík, S. Dražanová, V. Chotívka, J. Inorg. Nucl. Chem., 33, 1125-1133 (1971). (c) D. Wu, C. Niu, D. Li, Y. Bai, J. Alloy 
Compds., 374, $442-446$ (2004). (d) A. N. Turanov, V. K. Karandashev, A. N. Yarkevish, Z. V. Safronova, Solv. Extr. Ion Exch., 22, 391-413 (2004).

4) (a) J. S. Preston, Hydrometallurgy, 14, 171-188 (1985). (b) A. C. Du Preez, J. S. Preston, Solv. Extr. Ion Exch., 10, 207-230 (1992). (c) D. K. Singh, H. Singh, J. N. Nathur, Hydrometallurgy, 81, 174-181 (2006).

5) (a) H. Naganawa, K. Shimojo, H. Mitamura, Y. Sugo, J. Noro, M. Goto, Solv. Extr. Res. Dev., Japan, 14, 151-159 (2007). (b) K. Shimojo, H. Naganawa, J. Noro, F. Kubota, M. Goto, Anal. Sci., 23, $1427-1430$ (2007).

6) (a) A. Buch, D. Pareau, M. Stambouli, G. Durand, Solv. Extr. Ion Exch., 19, 277-299 (2001). (b) E. O. Otu, R. Chiarizia, P. G. Rickert, K. L. Nash, Solv. Extr. Ion Exch., 20, 607-632 (2002). (c) M. Mashimo, H. Sato, I. Komasawa, J. Chem. Eng. Japan, 30, $712-717$ (1997). (d) Y. Belaustegi, N. Etxebarria, M. A. Olazabal, L. A. Fernández, J. M. Madariage, J. Solution Chem., 23, 605-618 (1994). (e) Y. Belaustegi, N. Etxebarria, M. A. Olazabal, L. A. Fernández, J. M. Madariage, J. Solution Chem., 25, 1113-1124 (1996).

7) (a) S. Bukata, J. A. Marinsky, J. Phys. Chem., 68, 258-260 (1964). (b) K. Ohto, Y. Fujimoto, K. Inoue, Anal. Chim. Acta, 387, 61-69 (1999). (c) I. Van de Voorde, K. Latruwe, L. Pinoy, E. Courtijn, F. Verpoort, Solv. Extr. Ion Exch., 25, 809-829 (2007).

8) P. Comba, K. Gloe, K. Inoue, T. Krüger, H. Stephan, K. Yoshizuka, Inorg. Chem., 37, 3310-3315 (1998). 